\title{
Formação inicial e continuada de docentes: contribuições de um curso de formação sobre inclusão
}

\author{
Initial and continuing teacher training: contributions from a \\ training course about inclusion
}

Valesca Vargas Vargas Vieira ${ }^{1}$

Maria Rosa Chitolina ${ }^{2}$

\begin{abstract}
Resumo
A inclusão escolar e social de todos é imprescindivel. Porém, muitas vezes nos deparamos com grandes desafios relacionados a isso, assim, sempre devemos buscar conhecimentos e informação para aprimorar nossa formação. Neste sentido, o intuito desse trabalho foi verificar se as expectativas dos professores em formação inicial e continuada participantes de um curso de formação foram alcançadas e quais as contribuições do curso para estes, bem como, analisar os conhecimentos desses sujeitos sobre inclusão e tópicos relacionados a esse assunto. Os dados dos questionários inicial e final foram analisados por meio da metodologia de Análise Textual Discursiva. Com a análise dos resultados, podemos verificar que os professores percebem a importância da inclusão e o quanto um curso de formação pode contribuir para a formação tanto de professores em formação inicial quanto continuada. Assim, esse tema e outros relacionados precisam ser cada vez mais explorados para aprimorar os conhecimentos e ampliar as possibilidades de abordar assuntos referentes à inclusão.
\end{abstract}

Palavras-chave: Inclusão. Formação Inicial e Continuada. Curso de Formação. Deficiência Visual.

\section{Abstract}

The school and social inclusion of everyone is indispensable. However, we often come across major challenges related to this, so we must always seek knowledge and information to improve our education. In this regard, the aim of this work was to verify if the expectations of teachers, participants of a training course in initial and continuing education, were reached and what were the course contributions to them, as well as to verify their knowledge about inclusion and topics related to this subject. The data from the initial and final questionnaires were analyzed through the Discursive Textual

\footnotetext{
${ }^{1}$ Doutoranda em Educação em Ciência na Universidade Federal de Santa Maria, mestre em Educação em Ciências (2017) e graduada em Química Licenciatura Plena (2015) pela mesma instituição. E-mail: valesk.vvv@gmail.com.

2 Professora titular da Universidade Federal de Santa Maria no departamento de Bioquímica possui bolsa em produtividade em pesquisa nível 1B do CNPq e tem pós-doutorado no Albert Einstein College of Medicine/USA (2015). E-mail: mariachitolina@gmail.com.
} 
Analysis methodology. By analyzing the results, we can see that teachers realize the importance of inclusion and how much a training course can contribute to the training of both initial and continuing teachers. Thus, this and other related themes need to be increasingly explored to improve knowledge and expand the possibilities of addressing issues related to inclusion.

Keywords: Inclusion. Initial and Continuing Training. Training course. Visual Deficiency

\section{Introdução}

O fato que vem modificar o cenário da educação mundial fica por conta da elaboração da Declaração de Salamanca (ONU, 1994), que recomenda uma pedagogia centrada no aluno, ou seja, que atenda a suas necessidades sendo este um estudante com deficiência ou não. A mesma reafirma o direito de todos à educação, descreve que é preciso que as escolas reconheçam as várias necessidades dos alunos e a elas respondam, por meio de um currículo apropriado, modificações organizacionais, aprimoramento das estratégias e recursos de ensino, assegurando-lhes uma educação de qualidade em parceria com as comunidades.

Sendo que a escola acolhe sujeitos com aspectos múltiplos, sejam sociais, religiosos, politicos, ou seja, é um ambiente multicultural, diversificado, que recebe um público com objetivos, ideologias e necessidades diferenciadas. Nesse contexto, é imprescindível suprir as necessidades reais do sistema de educação, onde o papel da educação inclusiva deve ir além de favorecer o ingresso da pessoa com deficiência, é necessário garantir o sucesso do processo de ensino e aprendizagem e a permanência do estudante.

O movimento mundial pela educação inclusiva é uma ação política, cultural, social e pedagógica, desencadeada em defesa do direito de todos os estudantes de estarem juntos, aprendendo e participando, sem nenhum tipo de discriminação. A educação inclusiva constitui um paradigma educacional fundamentado na concepção de direitos humanos, que conjuga igualdade e diferença como valores indissociáveis (...) dentro e fora da escola (BRASIL 2008 , p. 1). Desta maneira, também contempla alguns temas propostos nos Objetivos de Desenvolvimento Sustentável (ODS) como o objetivo 4, que trata Interfaces da Educ., Paranaîba, v.10, n.30, p. 315 - 345, 2019 
de assegurar a educação inclusiva, equitativa, de qualidade e promover oportunidades de aprendizagem ao longo da vida, para todos.

A atual Base Nacional Comum Curricular (BRASIL, 2018, p.16) salienta o compromisso com a educação inclusiva, que "requer o compromisso com os alunos com deficiência, reconhecendo a necessidade de práticas pedagógicas inclusivas e de diferenciação curricular, conforme estabelecido na Lei Brasileira de Inclusão da Pessoa com Deficiência (Lei $\mathrm{n}^{\circ}$ $13.146 / 2015) "$.

Assim, o docente deve considerar cada aluno como único sendo determinante que o professor saiba lidar com as diferenças, entenda os limites de cada um e possa valorizar as suas potencialidades, percebendo que não há um padrão de aprendizagem e nem um aluno ideal. Assim, é indispensável considerar a formação do professor para a educação inclusiva como parte integrante do processo de formação geral, e não como um apêndice dos seus estudos ou um complemento.

Nessa perspectiva, a proposta de Diretrizes para a formação de professores da educação básica destaca o papel do professor, cujo foco é a formação para o exercício pleno da cidadania. Dentre os delineamentos para a docência, está: "assumir e saber lidar com a diversidade existente entre os alunos" (BRASIL, 2000, p. 5).

Nesse sentido, um programa de formação para professores configurase como um elo imprescindivel que deve unir a formação inicial ao desenvolvimento profissional ao longo da carreira docente, um programa que responde a concepção de que a formação de professores é um processo continuo que têm que ser oferecido de um modo adaptado as necessidades de cada momento da carreira docente (GARCIA, 1999).

De acordo com o autor, a iniciação ao ensino é um período que compreende a transição de estudantes para professores, neste período os professores são principiantes e estão formando sua identidade profissional, assim ainda podem ter dúvidas, tensões e expectativas, quanto a sua profissão.

Já a formação continuada deve permitir uma reflexão crítica sobre a prática e a reconstrução permanente de uma identidade pessoal e Interfaces da Educ., Paranaiba, v.10, n.30, p. 315 - 345, 2019 
profissional com interação mútua de modo a conduzir a uma prática acolhedora, sendo que a diversidade implica em uma via que contemple aspectos teóricos, práticos e atitudinais envolvendo a inclusão e a valorização das potencialidades dos seus alunos (FIGUEIREDO, 2008; MANTOAN, 2003a; MARTINS 2012).

Nesse sentido, foi ofertado para graduados e graduandos de Biologia, Física, Química e Educação Especial de uma universidade pública um curso de formação sobre inclusão voltado a conhecer mais sobre o universo de estudantes com deficiência visual. Nesse trabalho serão analisados os questionários inicial e final com o intuito de ponderar se as expectativas dos participantes foram alcançadas e quais as contribuições do curso de formação, bem como, verificar os conhecimentos dos participantes sobre inclusão e tópicos relacionados a esse assunto.

\section{Procedimentos metodológicos}

O projeto de pesquisa foi submetido ao Comitê de Ética em Pesquisa (CEP) da universidade pública na qual a pesquisa foi realizada e aprovado conforme parecer consubstanciado $\mathrm{n}^{\circ} 2.887 .807$ de 11 de setembro de 2018 .

A investigação em questão ocorreu por meio de um questionário inicial e outro final, disponilizado aos 24 professores em formação inicial e continuada dos cursos de Biologia, Física, Química e Educação Especial participantes do curso de formação disponibilizado à eles com duração de $30 \mathrm{~h}$ e com encontros presenciais e à distância. Os tópicos abordados ao longo do curso de formação encontram-se descritos no Quadro 1.

Quadro 1 - Tópicos abordados no curso de formação.

\begin{tabular}{|l|l|}
\hline \multicolumn{2}{|c|}{ Tópicos abordados no curso de formação } \\
\hline$\checkmark$ Conhecendo o universo da pessoa com deficiência visual: uma \\
abordagem da história e a Educação envolvendo a pessoa deficiente \\
visual; \\
$\checkmark$ Diálogo e troca de experiências com Educadora Especial; \\
$\checkmark$ Dicas de orientação e mobilidade; \\
$\checkmark$ Descrição de fotos referentes a acessibilidade ou falta dela; \\
$\checkmark$ Aula surpresa com participantes vendados; \\
$\checkmark$ Conversa com funcionário de uma insituição pública e formado em \\
\hline
\end{tabular}


pedagogia;

$\checkmark$ Conversa com professor de series iniciais cego;

$\checkmark$ Legislação referentes ao assunto;

$\checkmark$ Aprendizagem e Recursos Didáticos;

$\checkmark$ Relatos de Experiências e apresentação de materiais adaptados por estudante com deficiência visual;

$\checkmark$ Discussão sobre as propostas de conteúdos a serem abordados na elaboração de estratégias e recursos didáticos;

$\checkmark$ Elaboração estratégias e recursos didáticos adaptados para estudantes com deficiência visual;

Validação dos materiais e atividades elaborados no curso de formação por profissional com deficiência visual.

Fonte: Elaborado pelos autores.

As questões foram elaboradas com o objetivo de analisar os conhecimentos dos participantes sobre inclusão e tópicos relacionados a esse assunto, estas baseadas em Uliana (2015) e também verificar por meio das respostas dos graduados e graduandos, as expectativas e contribuições do curso de formação. Estas estão discutidas ao longo do trabalho, a pesquisa foi realizada com ênfase na abordagem qualitativa.

Para a análise dos dados utilizaremos a Análise Textual Discursiva (ATD), proposta por Moraes e Galiazzi (2006), segundo os autores o conjunto de documentos analisado é denominado de corpus, nessa pesquisa o corpus é definido como os questionários inicial e final. A partir dos quais realiza-se a unitarização que consiste na desmontagem ou desintegração dos textos destacando seus elementos constituintes, isto é, a análise para realização da categorização, onde ocorre a construção de relações entre as unidades combinando-as e classificando-as. A realização das etapas anteriores possibilita uma compreensão renovada do todo expressa em um metatexto (MORAES, 2003).

\section{Resultados e discussões}

Os participantes do curso de formação estão descritos no Quadro 2, de acordo com os cursos Química Licenciatura, Física Licenciatura, Biologia Licenciatura e Educação Especial, os quais são formados ou estão cursando, ou seja, são professores em formação inicial (FI) ou em formação continuada (FC). Os números foram distribuídos aleatoriamente com o intuito de não identificar os participantes. 
Quadro 2 - Participantes do curso de formação.

\begin{tabular}{|c|c|c|}
\hline Área & $\begin{array}{c}\text { Formação } \\
\text { inicial e } \\
\text { continuada }\end{array}$ & Participantes \\
\hline \multirow[b]{2}{*}{$\begin{array}{l}\text { Química } \\
\text { Licenciatura }\end{array}$} & FI & FI.1, FI.2, FI.3, FI.4, FI.5 e FI.6* \\
\hline & $\mathrm{FC}$ & $\begin{array}{l}\text { FC. } 1^{* *}, \text { FC. } 2^{*}, \text { FC } .3, \text { FC. } 4, \text { FC } .5 \text { e } \\
\text { FC. } 6\end{array}$ \\
\hline $\begin{array}{l}\text { Física } \\
\text { Licenciatura }\end{array}$ & FI & FI.7 \\
\hline \multirow{2}{*}{$\begin{array}{l}\text { Biologia } \\
\text { Licenciatura }\end{array}$} & FI & $\begin{array}{l}\text { FI.8*, FI.9, FI.10, FI.11, FI.12 e } \\
\text { FI.13 }\end{array}$ \\
\hline & FC & FC. 7, FC. $8^{*}$, FC.9* e FC. 10 \\
\hline $\begin{array}{l}\text { Educação } \\
\text { Especial }\end{array}$ & FC & FC. 11 \\
\hline
\end{tabular}

Fonte: Elaborado pelos autores.

Com base no quadro 1 podemos verificar que participaram do curso de formação 6 professores em formação inicial da Química Licenciatura e 6 em formação continuada. Também 1 licenciando da Física e 6 da Licenciatura em Ciências Biológicas em formação inicial e 4 em formação continuada dessa área. É necessário destacar que a pessoa do curso de Educação Especial (FC.11) é familiar de um participante e solicitou se poderia participar do curso, o que foi autorizado pelos demais participantes.

Os participantes que já são formados em outros cursos estão identificos por um asterisco $\left(^{*}\right)$ para poder diferenciá-los. O participante FI.6 já é formado em Química Bacharelado, o FC.2 é formado em Química Industrial e os participantes FI.8, FC.8 e FC.9 já são formados em Biologia Bacharelado, os dois asteriscos (**) representados no participante FC.1 é para informar que além da formação na licenciatura está fazendo Química Bacharelado.

Após a seleção das unidades de análise, passamos para o processo de categorização, que corresponde a uma classificação a partir dos materiais de análise, ao longo desse processo realizamos diversas aproximações de ideias que deram origem às categorias seguintes categorias: inclusão para todos, 
inclusão excludente, percepções sobre deficiência visual, incluir e integrar e ações que podem contribuir na formação de professores.

$\mathrm{Na}$ cartegoria inclusão para todos incluímos todas as características citadas no questionário inicial e final relacionadas a inclusão social, escolar e educação inclusiva, onde os participantes relacionaram tópicos de direito para todos, justiça social, medidas politicas, oportunidade e equiparidade de oportunidade, desenvolvimento da pessoa incluída, inclusão de todos, importante troca de experiência e aprendizados de todos os envolvidos, socialização, pensar e respeitar as diferenças, estimular a solidariedade, igualdade, humanização, sensibilização, aproximação entre diferentes, diminuição da desigualdade social, preconceito, fazer com que a pessoas se sintam incluídas e importantes, parte do todo, levando em conta suas necessidades, limitações e potencialidades, onde leva os envolvidos a aprimorar a sua formação, buscar recursos e adaptaçõe necessárias e também a saída do comodismo.

Isso nos mostra que os professores têm consciência da importância da inclusão tanto na sociedade, quanto na escola e a relação com a educação inclusiva e que de fao a inclusão deve ser para todos visando respeitar o outro e a diversidade, garantir o direito de todos, rompendo barreiras de preconceito, discriminações e intolerâncias. Como podemos observar por alguns relatos na sequência:

FI.8: oportunidades justas para todas as pessoas, não importando sua cor, classe econômica, opção sexual, gênero ou presença de alguma deficiência. A educação inclusiva, na teoria, é uma educação que não exclui nenhum aluno, que parte do pressuposto de que todos devem ter as mesmas oportunidades (...) deve proporcionar ferramentas e maneiras que possibilitem a aprendizagem de todo aluno, respeitando seu tempo e suas limitações, mas acima de tudo não pressupondo que o aluno não tem condições de aprender só pelo fato de ter uma deficiência.

FC.4: É a oportunidade de acesso e permanência, tanto de crianças, jovens e adultos, em processos de formação acadêmica (geral) e pessoal. A principal vantagem é a interação de todos os alunos, possibilitando o aprendizado em conjunto e principalmente, a troca de experiências. Além disso, possibilita que os demais estudantes (...), compreendam de que todos temos direitos a educação, com ou sem necessidades.

FI.11: (...) O ensino precisa permitir uma postura ativa de todos os estudantes. Quando a inclusão ocorre de forma correta, esse estudante não se sente excluído; Os demais estudantes aprendem e 
sensibilizam com a temática da inclusão; Os professores aprendem e desenvolvem metodologias inclusivas e diversificadas; A escola pode se tornar um ambiente em que os estudantes aprendem sobre a inclusão e se sentem confortáveis para estarem frequentando esse espaço.

FC.10: A educação inclusiva é uma forma de inserção de alunos no ensino básico, que tem como objetivo garantir a todos os alunos frequentarem as salas de aula do ensino regular, de forma livre de preconceitos e que reconheça e valorize as diferenças (...) é uma maneira na qual pode-se envolver todas as pessoas, sem exceção, em um sistema de ensino, independentemente de cor, idade, classe social e condições físicas e psicológicas. A escola inclusiva é um grande desafio a educação brasileira, pois implica em rever alguns aspectos, que envolvem desde o setor administrativo ao pedagógico. A vantagem de inserir estudantes em turma regulares, visa permanência desses alunos junto aos demais educandos, livres de qualquer forma de discriminação. Além de desenvolver o potencial dos alunos, atendendo suas necessidades.

De acordo com Costa $(2009$, 2012) incluir é pensar no diferente, no outro, na diversidade e refletir sobre a possibilidade de conviver juntos, mesmo que no grupo possam haver as diferenças. A inclusão social das pessoas com deficiência deve permitir a elas, o acesso aos serviços públicos, bens culturais e aos produtos decorrentes do avanço social, político, econômico e tecnológico da sociedade, respeitando as necessidades próprias da sua condição (BRASIL, 2002). A educação inclusiva é a transformação para uma sociedade inclusiva, se refere ao ensino para alunos com ou sem deficiências, com condições igualitárias para que todos possam desenvolver suas potencialidades, respeitando as individualidades.

Logo, sabe-se que a educação inclusiva não é uma tarefa fácil, é necessário enfrentar e superar desafios com a participação dos envolvidos com a educação, pois a inclusão é uma responsabilidade de todos e é indispensável as interações entre os alunos, familiares, professores, profissionais da educação, da saúde e também na articulação entre as diretrizes federais, estaduais e municipais (CAIMI; LUZ, 2018; NETO et al., 2018). Afinal, o desenvolvimento acontece do coletivo para o individual, de fora para dentro, de acordo com as relações e conexões estabelecidas no contexto social que a pessoa está inserida (VYGOTSKY, 2011).

Alguns desses tópicos também foram relatados como vantagens em ter estudantes com deficiência em turmas regulares. Todos esses assuntos também foram discutidos em vários momentos do curso, nos fazendo refletir 
em como agimos e o que podemos fazer para melhorarmos como seres humanos e a importância de sempre nos colocarmos no lugar do outro.

Desta maneira, como relatado por Uliana (2015), observa-se também que as vantagens mais salientadas pelos graduados e graduandos coincidem com os ideais que alavancaram o movimento da inclusão expresso em estudos já apresentados de Mantoan (2003b), Mendes (2006) e Mittler (2003). São elas: aceitação da diferença, trocas de experiências, aprendizado e desenvolvimento de todos os envolvidos, socialização, motivar, estimular e desenvolver as potencialidas. Assim, percebemos que os professores têm conhecimento sobre os benefícios do ensino inclusivo.

Outra categoria que emergiu da análise dos questionários foi a inclusão excludente, nesta levamos em consideração o que foi descrito pelos participantes como problemas relacionados ao despreparo, falta de formação e até disposição dos envolvidos no processo de inclusão, prática excludente, isso em todo o sistema educacional, falta de recursos pedagógicos, acessibilidade, currrículos adaptados, infraestrutura e assistência, déficit de pessoal para auxiliar no processo de inclusão como monitores e especialistas e atendimento educacional especializado (AEE), além de barreiras e discriminação impostas até por parte de receptividade das turmas que tem alunos incluídos, pois há casos em que estão presentes na sala, porém não são participantes de todo o processo, o que pode tornar o ensino massante e gerar dificuldade na aprendizagem, exclusão, ainda mudança de ritmo que pode prejudicar os envolvidos e o problema de salas de aula com muitos alunos. Como podemos observar pela descrição do participante:

FC.8: A principal desvantagem é o próprio sistema de ensino e a falta de capacitação/cursos de formação dos professores para pensar em práticas inclusivas. O sistema de ensino, basicamente, não está preparado para ter uma acompanhamento e desenvolvimento pleno desses indivíduos (...). Isso acaba de encontro com a falta de capacitação/cursos de formação para que os professores possam ter ferramentas que os auxiliem nesse percurso didático.

Podemos observar nessa categoria a consciência dos professores sobre a realidade de in/exclusão das escolas e que estes se mostraram preocupados diante da grande possibilidade de se tornarem professores de 
alunos com deficiência. Sendo que, não tiveram disciplinas que contemplem mais esses assuntos e os capacitem para atender as demandas de aprendizes com deficiência, algo também analisado no estudo de Uliana (2015). Referente a importância da preparação dos novos professores para a promoção da Educação Inclusiva Mittler pontua:

\begin{abstract}
Assegurar que os professores recentemente qualificados tenham uma compreensão básica do ensino inclusivo e de escolas inclusivas é o melhor investimento que pode ser feito a longo prazo. Isso assenta os alicerces para uma "boa prática" sobre as quais as gerações mais jovens poderão basear-se e oferecer condições para o surgimento de uma "massa crítica" de professores jovens que tiveram um pouco de compreensão e experiência da prática inclusiva. (2003, p.189).
\end{abstract}

Cabe ressaltar que esses professores, que não se sentem preparados para promover uma Educação Inclusiva, ao menos estão buscando formas de complementar a sua formação e percebem que também são responsáveis para a efetivação do processo de inclusão se mostrando sensibilizados com a causa.

Também, foi mencionado por alguns, se que de fato a inclusão está ocorrendo, analisando todos esses aspectos podemos perceber que esse processo é um grande desafio e muitas vezes não ocorre da maneira como deveria, isso também foi relatado por alguns participantes:

FI.8: (...) O simples fato dos alunos com deficiência estarem ocupando o espaço da escola não significa que eles estejam tendo alguma aprendizagem. A escola e os professores não estão preparados para receber os alunos com deficiência porque a formação é extremamente deficitária, e pouco está sendo feito para mudar essa realidade no âmbito das politicas públicas. Dentro da escola pouco é feito para incluir esse aluno aos demais e, principalmente por os profissionais não terem uma formação nesse sentido, quando são feitas tentativas nesse quesito ainda estamos muito calcados em métodos assistencialistas e paternalistas que só reforçam os estereótipos da deficiência. $\mathrm{Da}$ forma como vem ocorrendo atualmente eu não vejo muitas vantagens, principalmente quando falamos em "inclusão" de alunos com deficiência intelectual ou TEA (...) Já as desvantagens (...) a exclusão dos alunos sem deficiência para aquele com (justamente por não ser investido em acessibilidade atitudinal nas escolas e na sociedade), e salas com muitos alunos o que torna praticamente inviável a aprendizagem.

FC.3: obrigatoriedade não inclui, de fato, essas pessoas, tornando dicotômica a relação de inclusão e também aprendizagem. A inclusão social é muito importante e deve ser incentivada em todos os âmbitos da sociedade, porém acredita-se que da maneira como é realizada 
hoje não contemple as reais necessidades das pessoas com deficiência.

FI.11: Na minha opinião essa inclusão ocorre com pouca frequência Muitos professores acreditam estar incluindo um deficiente em sua dinâmica, mas na verdade estão integrando-o ao ambiente de sua aula, mas não estão incluindo-o a atividade em que todos ou a maioria está tendo condições para aprender com suas habilidades.

FC.11: Penso que se existir corretamente e o aluno tiver todos os atendimentos necessários para que realmente seja uma inclusão, sou muito a favor. Pois, o que vemos são escolas dizendo que tem inclusão escolar e o aluno está apenas "jogado" na escola, sem amparo algum. (...). Eles estando em turmas regulares já estarão fazendo com que ocorra uma socialização do aluno com os demais colegas, com a escola. E para que tudo ocorra bem, precisa que de acordo com sua necessidade sejam feitos materiais adaptados, para que esse aluno consiga de alguma forma acompanhar a turma, e que junto disso tudo, ele disponha de um monitor, para poder auxilia-lo quando necessário em sala de aula.

Esses relatos nos mostram a grande preocupação dos professores com o real processo de inclusão, como descreve Costa (2009), torna-se claro que a presença do estudante na escola, não garante efetivamente sua inclusão. Então o papel da Educação Inclusiva além de favorecer seu ingresso, garanta seu sucesso e permanência. É necessário que o objetivo da escola que preza pela educação inclusiva seja permitir que todos (as) possam contribuir para a formação de um conhecimento compartilhado, com igualdades de oportunidades, sem preconceito entre os diversos segmentos da escola para que tenham acesso e sucesso no processo de escolarização (BASTOS; CENCI, 2019; PACHECO et al., 2019)

A inclusão nos faz reconceituar a aula, o estudante, o professor, bem como, a sua formação, faz refletir sobre o ensinar e o aprender. A escola para todos é um ambiente em que se estabelecem relações de trocas entre as pessoas que nele habitam, "onde a deficiência perde o sentido definitivo atribuído a limitações de natureza cognitiva, sensorial, física, social, cultural", pois a convivência entre diversidades, singularidades, a liberdade de se fazer na diferença é o que realmente vale para o desenvolvimento do educando e a construção do conhecimento (MANTOAN, 2017, p. 45).

Quanto a categoria percepções sobre deficiência visual, inicialmente como podemos observar em algumas respostas os participantes responderam de maneira incompleta colocando apenas que são pessoas que não conseguem ver objetos, com visão debilitada, diferente do "normal, 
perda da visão, sem visão, com limitações, com déficit na visão, com pouca visão, baixa visão, pessoa que necessita de auxílio para ver e descrevendo uma porcentagem de visão ou descrevendo somente que é uma pessoa que não enxerga nada (FI.4, 5, 9, 11, 12, 13 e FC.1, 3, 4, 7) ou como o participantes FI.2 que respondeu de maneira incorreta. Porém, a maioria respondeu de forma mais completa, citanto perda parcial, visão parcial, baixa perda da visão, comprometimento parcial da visão, comprometimento da visão, baixa visão, limitação parcial ou total da visão e perda de visão, perda total da visão, pessoa que não consegue ver, cegueira, sem visão, ausência desse sentido, como podemos observar:

FI.2: É a pessoa que apresenta alguma deficiência desde astigmatismo, daltonismo até perda parcial ou total da visão.

FI.13: Pessoas com pouca visão que necessitam de diferentes recursos para aprender, viver em sociedade.

FC.4: Aqueles que apresentam um déficit visual, sendo de baixo, médio ou elevado grau FI.10: Pessoas que tem perda total ou parcial da visão.

FC.10: Uma pessoa sem visão/ou que possua sua visão parcialmente debilitada.

FI.8: É uma pessoa que tem uma limitação visual mais grave, que pode ser uma baixa visão ou a completa cegueira. Só um parênteses, fiquei pensando aqui porque outros problemas visuais não são considerados deficiência, como miopia por exemplo.

FC.11: Problemas na visão, baixa visão, cegueira.

Sendo que de acordo com Brasil (2001a) definem-se pessoas com baixa visão e cegueira como:

pessoas com baixa visão aquelas que apresentam desde condições de indicar projeção de luz até o grau em que a redução da acuidade visual interfere ou limita seu desempenho. (...) Pessoas com cegueira são as que apresentam desde ausência total de visão até a perda da projeção de luz. (BRASIL, 2001a, p. 34-35).

Analisando então o descrito anteriomente pelo autor, concluímos que no questionário final apenas 4 pessoas (FC.3, 4 e FI. 3, 4) responderam de maneira incompleta, relacionando apenas a pessoas que precisam de ajuda, compromete a realização de tarefas e um (FI.11) que descreveu que necessita de auxílio e destacou a cirurgia, sendo que na verdade a cirurgia não possibilita a correção da deficiência visual. No entanto, ao verificarmos a 
lista de presença percebemos que alguns desses participantes não estavam presente no dia da atividade que discutimos mais sobre pessoas com deficiência visual.

FC.4: Deficiente visual é toda e qualquer pessoa que apresenta alguma dificuldade visual em um grau mais elevado, que não é corrigido, somente, através do uso de óculos, mas sim que necessitam de materiais ampliados ou mesmo transcrito em braile.

FI. 3: É uma pessoa que não consegue enxergar como uma pessoa normal ou seja precisa de ajuda.

FI.11:Ter dificuldade de se orientar em um espaço pelo fato de não conseguir visualizar características ou componentes do ambiente em que está inserido, ou também, ter muita dificuldade e necessitar de auxílio de ferramentas (óculos, lentes, cirurgia) para conseguir visualizar os componentes do ambiente.

O restante dos participantes, no total 19, relacionaram a deficiência visual com a cegueira, perda da visão, sem visão ou baixa visão e muitos ainda complementaram as respostas, como podemos observar:

FI.2: É uma pessoa que não consegue enxergar (cegueira total) ou apresenta visão limitada (baixa visão).

FI.13: Pessoa com baixa visão ou pessoa cega.

FI.10: Pessoa que nasceu sem a visão, ou perdeu a mesma ao longo da vida, pessoas com baixa visão e qualquer um que precise de materiais didáticos adaptados para ajudar na compreensão dos conteúdos abordados nos diversos níveis de ensino, tanto fundamental e médio, até o superior.

FC.10: Deficiente visual é uma pessoa que caracteriza-se pela limitação ou perda da funções básicas do olho e do sistema visual. O deficiente visual pode ser a pessoa cega ou com baixa visão.

FI.8: É uma pessoa que tem uma limitação visual que não pode ser corrigida através de cirurgia, podendo ser uma baixa visão ou a completa cegueira.

Quanto aos conhecimentos referentes a categoria incluir e integrar no questionário inicial apenas 5 participantes (FI.4, 5, 8, 13 e FC.6) conseguiram distinguir esses temas, 4 (FI.11 e FC.1, 5, 11) não sabem ou não quiseram opinar e os demais responderam de maneira incorreta, como podemos analisar em algumas respostas:

FI.5: Sim. Na inclusão, ocorre total participação das pessoas, em todos momentos. Na integração, as pessoas fazem parte do grupo, mas sem obrigatoriamente estarem inclusas.

FI.8: (...) Integração tem a ver com integrar a pessoa com deficiência na sociedade. Ela está lá, com todos os outros que não tem 
deficiência, mas não participa ativamente das decisões e não se mistura com os demais. Ocupa o mesmo espaço, mas continua com os seus semelhantes. Já inclusão é incluir a pessoa com deficiência na sociedade, e isso significa que ela faz parte daquele espaço como qualquer outra pessoa. Não está (ou não deveria estar) segregada dos demais.

FC.3: Incluir me remete a inserir (adicionar ao grupo). Integrar parece-me estar atrelado à tornar parte do grupo, com sentimento de pertencimento.

FC.8: Sim, educação inclusiva preve a integração desses indivíduos no ambiente escolar, mas não só isso. Prevê que o ensino e o desenvolvimento cognito seja aprimorado.

Integrar significa inserir a pessoa na sociedade ou o aluno, no caso do ambiente escolar, nos espaços físicos das instituições de ensino regular, mas sem a obrigatoriedade de ser na sala de ensino regular e como destaca Milttler (2003, p. 35) “o estudantes deve adaptar-se à escola, e não há necessariamente uma perspectiva de que a escola mudará para acomodar uma diversidade cada vez maior de estudantes". Neste aspecto Mantoan (2003a, p.18) acrescenta que "trata-se de uma concepção de inserção parcial, porque o sistema prevê serviços educacionais segregados”. Assim, o enfoque da integração foi considerado insuficiente e limitado por não considerar os alunos que precisavam de uma resposta educativa individualizada e como salientam Sanches e Teodoro (2006, p. 69):

A experiência adquirida com a integração escolar e toda a reflexão que a mesma gerou sobre a escola que exclui uma parte considerável dos seus alunos, não somente os que se encontram em situação de deficiência, ajudou a desencadear o movimento da inclusão que pretende promover o sucesso pessoal e acadêmico de todos os alunos, numa escola inclusiva.

No questionário final, referente a categoria incluir e integrar somente 3 participantes explicaram apenas sobre inclusão (FC.4, 5 e 7) e 3 (FI.1, 4 e FC.1) inverteram a explicação dos termos. No entanto, os demais, argumentaram de forma mais completa, como podemos verificar em algumas das seguintes respostas:

FI.11: Sim, existem diferenças. Por exemplo, integrar uma pessoa com deficiência a um espaço (de qualquer âmbito) é permitir que ela esteja presente nesse ambiente, mas desempenhe funções diferentes ou adaptadas apenas para ela exercer, devido as suas "delimitações". Por outro lado, o incluir envolve uma mudança de estrutura, planejamento, metodologia, recursos, para que todos os envolvidos em um ambiente, seja ele escola, trabalho, rua, ambientes variados, 
possam participar de forma igualitária, sem que ninguém deixe de participar ou de ter oportunidades devido a uma deficiência. $O$ incluir privilegia a diversidade como um todo, e usa essa diversidade como ferramenta para elaborar condições positivas de oportunidades de participação.

FC.3: Sim, integrar, é conduzir a pessoa com deficiência no espaço escolar. Inclusão é tornar essas pessoas parte do processo, com atendimento especializado, significativo e de qualidade.

FC.8: Sim, existe. Integração é colocar o indivíduo para socializar com os demais dentro da perspectiva escolar. Inclusão é "olhar" para esse individuo de maneira que ele possa desenvolver, dentro de suas limitações, todo o seu potencial a respeito dos conhecimentos para usá-los durante sua trajetória de vida.

Podemos perceber que no dicionário como também explicita Ulina (2015) os termos incluir e integrar são semelhantes, porém no âmbito educacional eles são bem diferentes e na prática, as vezes por falta de conhecimento são tidos como sinônimos. No entanto, não basta eu integrar o aluno na escola em sala de aula regular, simplesmente ele estar presente lá, é necessário incluir esse estudante permitindo que todos possam estudar juntos nas escolas de ensino regular, e serem atendidos nas suas particularidades, isso também vale para a sociedade no geral.

No questionário inicial descrevemos algumas ações que podem contribuir na formação de professores para atuarem e promoverem um ensino inclusivo e solicitamos que os professores sinalizassem as que eles consideram mais importantes para compor a formação, tendo em vista a inclusão de alunos com deficiência.

No Quadro 3 apresentamos as ações e a quantidade de respostas de acordo com o assinalado pelos professores, cabe ressaltar que dois professores marcaram todas as ações como importantes no processo de formação, dois na opção outras adicionaram as duas últimas opções e os demais assinalaram quantidades variadas de ações.

Quadro3 - Ações para aprimorar a formação de professores frente à inclusão.

\begin{tabular}{|l|c|}
\hline \multicolumn{1}{|c|}{ Ações } & Respostas \\
\hline Curso de Libras. & 18 \\
\hline Curso de Braille. & 12 \\
\hline Curso de Audiodescrição. & 6 \\
\hline Grupos de estudos para discutir a temática Inclusão. & 16 \\
\hline Tornar obrigatório o estágio em sala de aula que possuem & 8 \\
\hline
\end{tabular}




\begin{tabular}{|l|c|} 
estudantes com deficiência. & 19 \\
\hline $\begin{array}{l}\text { Incorporar nas ementas das diversas disciplinas pedagógicas a } \\
\text { Educação Inclusiva. }\end{array}$ & 16 \\
\hline $\begin{array}{l}\text { Disciplinas que apresentem e discutam especificidades, } \\
\text { limitações e potencialidades de cada tipo de deficiência. }\end{array}$ & 22 \\
\hline $\begin{array}{l}\text { Oficinas para elaborar materiais pedagógicos que atendam a } \\
\text { demanda de estudantes com deficiência. }\end{array}$ & 17 \\
\hline $\begin{array}{l}\text { Cursos sobre as novas tecnologias da informação e da } \\
\text { comunicação como metodologias de estudo relacionadas com a } \\
\text { Educação Inclusiva. }\end{array}$ & 1 \\
\hline $\begin{array}{l}\text { Discutir nas disciplinas da licenciatura mais sobre as } \\
\text { diferenças, tirar da cabeça a ideia do aluno ideal, perfeito, que } \\
\text { atende a todas as indicações do professor, porque esse aluno } \\
\text { não existe, ou é muito raro. }\end{array}$ & 1 \\
\hline $\begin{array}{l}\text { Formação continuada para professores que atuam } \\
\text { principalmente na educação básica }\end{array}$ & \\
\hline
\end{tabular}

Fonte: Elaborado pelos autores.

Analisando o quadro podemos verificar que a opção “Oficinas para elaborar materiais pedagógicos que atendam a demanda de estudantes com deficiência" foi a mais sinalizada, como também destaca Uliana (2015) adaptar materiais que atendam as demandas dos alunos com deficiência é destacado em estudos de Camargo (2012) e Costa (2012), sendo essencial para promover um ensino que possibilite incluir todos os estudantes no processo de aprendizagem. A segunda opção foi "Incorporar nas ementas das diversas disciplinas pedagógicas a Educação Inclusiva”, isso nos mostra a preocupação dos graduados e graduandos com a presença desse importante tema em seus currículos, o que pela análise realizada dos currículos dos cursos de Biologia, Física e Química licenciatura dos professores em formação inicial não vêm ocorrendo.

Também no espaço para sugestões e comentários um participante colocou que devíamos "estender o curso as outras licencituras p/ que todos tenham acesso a temática, visto que no currículo das licenciaturas o assunto é pouco explorado", corroborando com o resuldao anterior de que as disciplinas abordam pouco esse assunto.

$\mathrm{Na}$ sequência encontra-se descrita a avaliação do curso de formação, pontos postivitos e negativos e a relação entre as expectativas e as contribuições do curso para a formação inicial e continuada dos professores. 
No Quadro 4 estão descritos os pontos positivos e negativos que os participantes destacaram relacionados ao curso de formação, esses dados foram retirados das anotações feita no questionário final.

Quadro 4 - Pontos positivos e negativos destacados pelos participantes do curso de formação.

\section{Pontos positivos}

$\checkmark$ O curso de formação nos oferece uma oportunidade que a nossa graduação não, o contato com alunos com deficiência visual, e isso é muito importante na nossa formação como professores;

$\checkmark$ O curso abordou um tema bastante relevante, aprofundando e trazendo novos conhecimentos sobre materiais, conceitos, legislação, curiosidades, fatos, entre outros;

$\checkmark$ Curso bem esquematizado, estruturado, objetivo, muito importante e esclarecedor, envolvendo uma variedade de informações e aspectos importantes dessa temática;

$\checkmark$ Todas as atividades tinham um propósito e a cada dia tinham diferentes atividades, algumas lúdicas;

$\checkmark$ Preparação e organização da professora, que desde o início deixou bem claro os objetivos do curso, bem como o cronograma e a disposição à sanar dúvidas e buscar informações além;

$\checkmark$ Atividades extraclasse que faziam pensar além das aulas sobre a deficiência visual, mas não sendo muito teóricas ou extensas;

$\checkmark$ Temas/aulas foram bem apresentados, com aulas diferentes e dialogadas, a didática e dinâmica da doutoranda fez ter envolvimento com o assunto e com o curso, com espaço para discussão, comentários e intervenções sempre interagindo com os participantes;

$\checkmark$ Clima descontraído e de debate formativo, não só a pesquisadora passava o conteúdo, permitia-se que os participantes pudessem contrinuir com o andamento das "aulas", imporante engajamento dos participantes;

$\checkmark$ Forma leve, alegre e humana com que os conteúdos foram apresentados;

$\checkmark$ Troca de conhecimentos e experiências entre colegas com diálogo em coletivo envolvendo discussões e debates de ideias, com diálogo e participação de todos, boa interação entre o grupo;

$\checkmark$ Conversa entre cursos diferentes, ajuda a perceber como esses assuntos são vistos, pois mesmo pertencendo a mesma instituição, cada um tem seu dialéto, opiniões e pensamentos intrinsecos, interação entre as áreas torna as discussões mais ricas e contrutivas;

$\checkmark$ Trocas, reflexões, aprendizagens de todos os participantes e convidados do curso;

Visitas das pessoas com deficiência visual e profissionais da área, 
trouxeram visão necessária para melhor compreensão dos temas abordados e da realidade vivenciada;

$\checkmark$ Visita da educadora especial e materiais didáticos apresentados;

$\checkmark$ A Ed. Especial falando do aluno e do trabalho que desenvolve com ele e com a escola. Total dedicação e dando muita autonomia para o aluno;

$\checkmark$ Conversa com uma profissional da área foi muito enriquecedora e norteadora para termos uma noção de que o trabalho com esses estudantes também é negligenciado e não é as “mil maravilhas", e que precisa de maior atenção e compreensão de diversas partes, tanto dos estudantes, quanto professores, pais e sociedade em geral;

$\checkmark$ Contato direto com uma pessoa deficiente visual, para quebrar alguns tabus que tínhamos em relação a essas pessoas;

$\checkmark$ Aula vendada foi muito interessante, é preciso tomar cuidado pois nós "videntes" nunca vamos nos sentir igual as pessoas com deficiência visual, pois eles já estão adaptados com essas condições;

$\checkmark$ Forma que a doutoranda propôs de pensarmos atividades para os alunos ficou bem dinâmico;

$\checkmark$ Elaboração dos materiais e estratégias didáticas e ideias dos modelos apresentados pelos colegas;

$\checkmark$ Poder pensar atividades específicas para os alunos, (re)pensarmos a nossa prática, conhecer novos materiais;

$\checkmark$ Poder aplicar a atividade pensada para o aluno e ver que ela deu certo e que o mesmo achou interessante o fato de termos levado os modelos confeccionados por nós;

$\checkmark$ Materiais didáticos que achei que seriam coisas extremamente complexas e caras de fazer, entretanto são coisas mais simples do que imaginei;

$\checkmark$ Confecção dos matérias e a aplicação desses, pois nos propiciaram o contato com os alunos;

$\checkmark$ Troca de ideias sobre situações não comuns a alguns participantes;

$\checkmark$ Aprendizado de vários termos, de como lidar em determinadas situações, bem como, conhecer como as pessoas utilizam a bengala, cão-gia, braille, entre outros

$\checkmark$ Aprendizagem prática;

$\checkmark$ O curso teve muitos momentos dinâmicos e práticos que permitiram conhecer mais o universo de pessoas deficientes visuais e de como podemos trabalhar com elas;

$\checkmark$ São cursos como esses que precisamos para nos ajudar e nos dar um norte para como trabalhar com esses alunos;

$\checkmark$ Pontualidade e organização, carga horária boa e bem distribuída;

$\checkmark$ Formato flexível de horários e dias, importante para que todos pudessem ser atendidos;

$\checkmark$ Disponibilidade, coordenação, comunicação, organização e dedicação da propositora do curso, assim como a utilização de um grupo em rede social para troca de informações entre os participantes do curso.

Horário dos encontros;

Pontos negativos 
$\checkmark$ Excesso de questionários;

$\checkmark$ Falta de tempo para a aplicação dos materiais com os alunos ao longo do curso;

$\checkmark$ Forma mais dinâmica para discutir legislação (vídeos ou fazer o uso de outros recursos);

$\checkmark$ Forma como abordada em sala de aula no momento da visita do aluno com deficiência visual, filmagens e fotografias por parte dos participantes durante a conversa, também solicitação de que fizesse alguma atividade como ler, escrever "mostrando que sabe";

$\checkmark$ Tratar a pessoa com deficiência como se fosse um milagre estar vivendo a vida, como uma atração. Falta de organizar o que seria perguntado, ter um direcionamento na visita;

$\checkmark$ Falta de abordar questões referentes a acessibilidade atitudinal, cuidado para não reforçar padrões assistencialistas nem esteriótipos da pessoa com deficiência, não salientar a falta da visão e sim reforçar a naturalidade;

$\checkmark$ Atividade vendados poderia ser dividida em dois momentos: uma parte sem adaptação e outra parte com adaptação sobre o mesmo conteúdo;

$\checkmark$ Conversa com educadora especial muito simples, poderia ter tido mais visões sobre como educadores especiais "lidam" com a deficiência;

$\checkmark$ Tempo foi um pouco curto o que impediu de visitar mais lugares;

$\checkmark$ O curso deveria ser mais longo e não somente a duração de um semestre, pois é muita coisa em pouco tempo;

$\checkmark$ Poderiamos ter mais tempo para pensar nas atividades, bem como apresentar o que já se tem sobre materiais adaptados para alunos com deficiência visual;

$\checkmark$ Fornecer material em forma de apostila dos assuntos abordados. Fonte: Elaborado pelos autores.

Referente aos pontos positivos do curso os participantes relataram que este é uma importante oportunidade que a graduação não fornece, que o tema é muito relevante envolvendo uma variedade de informações, bem estruturados com objetivos claros e que cada atividade tinha um propósito e ainda as atividades à distância faziam pensar além dos encontros. Muito importante ressaltar, que os participantes tiveram amplo espaço para expor suas ideias e discutir os tópicos com os colegas, gerando uma grande troca de ideias e compartilhamento de conhecimentos, entre as diferentes áreas de formação. As visitas das pessoas com deficiência visual (alunos e professores) e profissionais da área trouxeram visão necessária para melhor compreensão dos temas abordados e a realidade vivenciada, bem como, os recursos didáticos mostrados, foram importantes para quebrar alguns tabus Interfaces da Educ., Paranaíba, v.10, n.30, p. 315 - 345, 2019 
que tínhamos em relação a pessoas com deficiência fatos muito bons e válidos.

Quando os docentes destacam que se sentem mais preparados para a promoção de ensino de sua área para estudantes com deficiência isso se deve ao contato prático e a troca de experiências evidenciada ao longo do curso, como destaca Tardif $(2012$, p.49) os saberes práticos "formam um conjunto de representações a partir das quais os professores interpretam, compreendem e orientam sua profissão e sua prática cotidiana em todas as suas dimensões. Eles contituem, por assim dizer, a cultura docente em ação".

Destacaram também sobre a aula surpresa, na qual estavam vendados e o quanto é importante nos colocarmos no lugar do outro, mas salientamos à eles que sem dúvidas, jamais iremos nos sentir igual as pessoas com deficiência visual, mas sim essa atividade serviu para refletirmos a importância de adaptarmos materiais para os alunos. Ressaltaram a elaboração dos materiais e estratégias didáticas e as ideias dos modelos apresentados pelos colegas como interessante, pois é necessário sempre (re)pensarmos a nossa prática e estarmos abertos para novos conhecimentos e desafios. Ainda salientaram o aprendizado de vários termos, de como lidar em determinadas situações, bem como, conhecer como as pessoas utilizam a bengala, cão-guia, braille, entre outros. Também, relataram sobre a organização e dedicação na pesquisa da doutoranda, pontualidade, carga horária boa e bem distribuída e o formato flexível de horários. E com todos esses pontos positivos relatados ficamos gratos e satisfeitos, no entanto, entre esses destacados um que concordamos plenamente e pensamos ser essencial para a nossa formação é que precisamos de cursos assim para nos ajudar e auxiliar em como trabalhar com esses alunos e complementar a nossa formação.

Resultados semelhantes foram destacados no trabalho de Uliana (2015), a qual salientou que ao participar do curso de formação os professores tiveram tempo e a oportunidade de aprimorar os seus saberes e desta maneira sentirem-se mais preparados e também propensos a impulsionar uma inclusão e Educação Inclusiva conforme também defendido 
por estudiosos como Mantoan (2003b) e Mittler (2003). Ainda Veiga (2009) identifica a formação docente como sendo um processo interminável, ampliando-se em um contexto coletivo, tomando uma postura mais produtiva quando é compartilhada, o que de fato pode ser evidenciado ao longo do curso.

Quanto aos pontos negativos alguns participantes acharam ruim os horários do curso por ser a tardinha. No entanto, foi esse o horário que a maioria pode participar. Quanto ao excesso de questionários concordamos que talvez tenham sido muitos, mas na verdade fizemos mais questionários para não colocar um número tão grande de questões em cada um deles. A falta de tempo para a aplicação das atividades realmente pode tornar-se um desafio em um curso de apenas 30h, em que abordamos todos os tópicos referentes ao assunto, desenvolvemos as estratégias e recursos didáticos e ainda aplicar as atividades, por esse motivo, nosso objetivo inicial era somente elaborar o material e aplicar em um outro momento com os participantes que tivessem interesse.

No encontro que teve a participação de um estudante cego alguns participantes do curso não gostaram da maneira como a educadora especial, o monitor e outros participantes abordaram o aluno, solicitando que em uma próxima vez sejam discutidos previamente o que será conversado e talvez abordar mais sobre questões referentes a acessibilidade atitudinal. Quanto a atividade vendados sugeriram que pudesse ser dividida em dois momentos, uma parte sem adaptação e outra parte com adaptação sobre o mesmo conteúdo. Alguns acharam a conversa com educadora especial muito simples, descreveram que poderia ter mais visões sobre como educadores especiais "lidam" com a deficiência, na verdade eles gostariam que tivesse a participação de mais profissionais da área para conhecer as suas opniões e experiências, mas é algo complicado para o tempo do curso, o qual também pediram que fosse maior, mas isso seria bem dificil visto que, muitos participantes ainda são graduando e seus horários alteram de um semestre para o outro. Também solicitaram que fossem fornecidos materiais em forma de apostila sobre o curso, porém todas as apresentações, referências e vídeos foram postados no grupo e enviados por e-mail. Acreditamos que o relato de Interfaces da Educ., Paranaíba, v.10, n.30, p. 315 - 345, 2019 
aspectos negativos do curso também são de grande valia para que possamos melhorar cada vez mais.

Segundo Garcia (2008 p. 592) "as abordagens educacionais direcionadas aos alunos com deficiência não devem se pautar numa visão romântica, idealista, ou exclusivamente técnica, nem mesmo numa perspectiva filantrópica ou protecionista". Nesta perspectiva, a troca de informações, ajuda mútua, estudos conjuntos, diálogo e o trabalho coletivo envolvendo pais, profissionais especializados, funcionários, gestores e professores, são essenciais para desenvolver os processos inclusivos como citado por Cami e Luz (2018). Para oferecer uma educação de qualidade para todos, é necessário melhorias no processo educativo, propondo condições de desenvolvimento na educação especial.

A atuação do docente é envolvida por constantes mudanças, em virtude dos novos acontecimentos, descobertas e conhecimentos, assim, segundo Silva e Mól (2019) a importância da formação continuada está em aperfeiçoar seus conhecimentos e aprimorar o desempenho de suas atribuições. Sendo que os processos de reflexão sobre a prática pedagógica e a formação continuada são importantes e fundamentais, para promover a conscientização sobre valores humanos, repensar a própria prática e encontrar caminhos para solucionar os problemas.

A seguir, no Quadro 5, estão descritas as possíveis contribuições do curso para os professores em formação inicial e continuada e, sobre suas expectativas com relação ao mesmo. As informações estão descritas de maneira geral, sendo que os participantes não estão discrimidados individualmente.

Quadro 5 - Expectativas e contribuições do curso de formação.

Expectativas foram superadas;

$\checkmark$ Aprendi muito mais do que poderia imaginar;

$\checkmark$ Atividades práticas e diálogos com os profissionais da área forma enriquecederas;

$\checkmark$ Visão complementar aos assuntos e mostraram que a realidade não é tão acessivel quanto se imagia;

Visita do estudante com deficiência visual foi muito esclarecedora; 
$\checkmark$ Aprendi com as ideias, vivências e olhares dos colegas participantes do curso;

$\checkmark$ Trocas de experiências e conversas sobre o assunto;

Mostrou que preciso buscar mais conhecimentos;

$\checkmark$ Assuntos abordados complementaram e trouxeram novos conhecimentos;

$\checkmark$ Pensar, dialogar e se deparar com questões que normalmente não tem acesso;

$\checkmark$ Boa experiência, apredi coisas que antes, nem passavam pela minha cabeça, conceitos, informações, tipos de materiais;

$\checkmark$ Possivel a partir do curso, mudar de forma positiva o olhar para com alunos com deficiência;

$\checkmark$ Mostrou que pequenos gestos dentro e fora da sala de aula fazem/farão toda a diferença;

$\checkmark$ Expectativas foram alcançadas em partes, acredito que faltou maior explanação sobre materiais didático;

$\checkmark$ Falta de aprofundamento das questões referentes a acessibilidade atitudinais;

Desenvolver um olhar mais humano;

$\checkmark$ O curso foi de valia para minha formação enquanto pessoa humana e professora;

$\checkmark$ Possivel perceber e denotar alguns pontos importantes de uma relação aluno-professor, como por exemplo, ter um olhar crítico e ao mesmo tempo cuidadoso voltado ao ensino que tenham decificência;

$\checkmark$ Despertar para situações cotidianas que antes passariam despercebidas e podem ser mudadas;

$\checkmark$ Tratar nossos alunos como únicos, nenhum aluno aprende igual e por isso temos que repensar nossas atividades e dar o melhor de nós;

$\checkmark$ Olhar mais consciente e empático sobre estruturas, locais, comportamentos, visualizar de uma forma mais responsável a situação;

$\checkmark$ O curso não contribuiu apenas para a minha formação profissional, como também para a minha formação social como cidadão, que despertou meu olhar e atenção para essa temática de uma forma mais critica e ativa;

$\checkmark$ O curso proporcionou enxergar e pensar mais nas pessoas com deficiência, aprendi que todos merecem ter uma boa aula e na maioria das vezes não é dificil adaptar as aulas para os diferentes públicos;

$\checkmark$ Mudança de concepção sobre as pessoas com deficiência visual, tanto a forma de abordagem cotidiana, quanto o ensino inclusivo, antes tinha ideia mais voltada para integração do que para a inclusão em si desses alunos;

$\checkmark$ Olhar diferente sobre a acessibilidade "abre" a forma de ver o espaço que estamos inseridos, perceber que podemos melhorar nos pequenos detalher, como por exemplo, tirar uma cadeira que seria um obstáculo; 
$\checkmark$ Troca e compartilhamento de experiências e ideias entre os colegas do curso foi muito válida, permitindo o amadurecimento pessoal e valorização profissional que tem essa preocupação com a temática inclusão, bem como observar outras perspectivas sobre o assunto;

$\checkmark$ As trocas, os diálogos, as dinâmicas, permitiram que percebesse a importância de um trabalho educacional com pessoas deficientes visuais;

$\checkmark$ Interação entre pessoas que ainda estão na graduação e outros que já saíram, e podemos ver que ambos tem dúvidas e curiosidades sobre a DV e as demais deficiências;

$\checkmark$ Reflexões sobre a história nos fez compreender os motivos de ainda não termos acessibilidade para pessoas com deficiência visual e qua a luta por direitos é constante, mesmo que legislações imponham ações;

$\checkmark$ Desenvolver um processo de empatia com a pessoa deficiente visual;

$\checkmark$ Importância de colocar-se no lugar do outro além de tornar o olhar ao próximo com mais cuidado;

$\checkmark$ Aula surpresa foi importante para refletir melhor sobre o processo de adaptação de material;

$\checkmark$ Atividades fora da sala de aula, foram importantes para observar o cotidiano ou acrescentar no mesmo um olhar diferenciado sobre deficiência visual;

$\checkmark$ Perceber que simples mudanças podem facilitar e tornar a vida mais acessivel à eles;

$\checkmark$ Ampliação dos conhecimentos sobre formas para trabalhar com pessoas com deficiência visual;

$\checkmark$ Conhecer alunos com a deficiência visual e a partir do contato com esses alunos planejariamos e iriamos aplicar as atividades foi sensacional;

$\checkmark$ Através do curso consegui ter acesso a diferentes aplicativos, recursos didáticos e exemplos de materiais que podem ser adaptados;

$\checkmark$ Aprendi termos mais corretos de serem utilizados e de como abordar uma pessoa com deficiência visual;

$\checkmark$ Graduação contempla apenas uma disciplina que destaca só aspectos de Ed. Especial, curso de formação oferece mais segurança para desempenhar função como professor de modo a contemplar alunos videntes ou não;

$\checkmark$ Pensar em maneiras alternativas, métodos práticos de preparar aulas para alunos com deficiencia visual. Pensar também como um material didático pode auxiliar um aluno com deficiência visual e conhecer alguns dos recursos didáticos possiveis para trabalhar junto aos alunos com deficiência visual;

$\checkmark$ Sensibilização de que os educadores podem e devem repensar a prática para verdadeiramente incluir o aluno com deficiência;

$\checkmark$ Importância do braille, que é possivel planejar uma atividade de maneira fácil para o professor e eficiente para o aluno, a importância das cores e de ampliar os materiais quando necessário;

Curso abriu horizontes para trabalhar com o assunto e conhecer 
mais sobre;

$\checkmark$ Permitiu que alargasse meu leque de possibilidades quanto ao trabalho com pessoa deficiente visual, qualificando minha formação enquanto professora.

$\checkmark$ Com a elaboração do material didático fiquei mais criativa para outras ideias que pretendo fazer e aplicar em sala de aula com os alunos;

$\checkmark$ Importante tanto na elaboração de aulas que facilitem aprendizado quanto na forma de agir, conversar, guiar, descrever imagens;

$\checkmark$ Sentem-se mais preparados e sabem onde buscar a informação se necessária, pois o curso mostrou diferentes possibilidades;

$\checkmark$ Entender algumas dicas que podem auxiliar em futuros encontros com alunos ou qualquer pessoa com deficiência na escola ou na rua, noções de orientação e mobilidade de pessoas com deficiência visual;

$\checkmark$ Abordados diversos tópicos antes não vistos ou nem ao menos compreendidos, como legislação vigente, história, processo de ensino, após o curso amplia o olhar sobre a temática;

$\checkmark$ Relatos e vivências do aluno com deficiência visual e sua educadora especial que salientaram que além de ensiná-los sobre conteúdos é preciso de ensiná-los para a vida, axiliando a serem independentes, participação deles foi fundamental, colocações muito relevantes e gratificantes;

$\checkmark$ Conhecer mais sobre a profissão do educador especial e os diversos obstáculos;

$\checkmark$ Despertar o interesse em aqdquirir mais conhecimentos e procurar comparecer a ais atividades sobre inclusão que são de extrema importância para a formação pessoal e profissional;

$\checkmark$ Curso motivou a buscar mais informações e conhecimentos sobre pessoas com deficiência e participar de mais atividades relacionadas a esse assunto;

$\checkmark$ Perceberam o quanto as discussões sobre educação inclusiva é muito necessária dentro das universidades e nas escolas com alunos e professores.

Fonte: Elaborado pelos autores.

Percebeu-se que o objetivo do curso foi alcançado em virtude dos relatos de alguns participantes de que, suas expectativas foram superadas com relação ao aprendizado, além das atividades práticas e conversas com pessoas com deficiência visual e profissionais da área, reportadas como muito enriquecedoras, perceberam que, a realidade, às vezes, não é tão acessivel quanto imaginavam e também a importância de buscarem novos conhecimentos além de aprimorarem os pré-existentes. Relataram ainda, que, a partir do curso puderam mudar de forma positiva o olhar para com alunos com deficiência e que o mesmo evidenciou que, pequenos gestos 
dentro e fora da sala de aula fazem toda a diferença. Apenas dois participantes destacaram que suas expectativas não foram alcançadas ou foram em partes, pois um descreveu que faltou maior explanação sobre materiais didático e outros que faltou aprofundamento das questões referentes a acessibilidade atitudinais, pontos estes relevantes e que serão repensados para uma próxima oportunidade.

Referente as contribuições para a formação dos professores esses relataram um leque de contribuições, algumas dessas já mencionadas nos pontos positivos, mas também complementaram que a partir do curso desenvolveram um olhar mais humano, crítico e cuidadoso voltado ao ensino de pessoas com deficiência, entenderam que cada aluno é único, a importância de se colocarem no lugar do outro e também despertar para situações cotidianas que antes passariam despercebidas, aspectos que realmente gostariamos muito que eles percebessem e levassem para a vida. Salientaram que mudaram suas concepções sobre as pessoas com deficiência visual, percepções a respeito da importância de adaptar as suas aulas, conhecer diferentes aplicativos, recursos didáticos, estratégias e termos corretos que podem ser utilizados.

Como também evidenciado por Uliana (2015), o curso de formação contribui para a ampliação e aprimoramento de saberes docentes, assim novos saberes sobre inclusão foram agregados aos conhecimentos dos professores participantes, gerando também mudanças nas percepções que os licenciandos tinham sobre inclusão, principalmente, de estudantes com deficiência visual, fazendo com que os docentes se sentissem mais preparados para a promoção de um ensino nesse sentido.

Muitos destacaram que o curso não contribuiu apenas para a sua formação profissional, mas para a sua formação pessoal e social, que as troca, diálogos, dinâmicas e compartilhamento de experiências e ideias entre os colegas do curso e também com os visitantes, foi muito válida, permitindo o amadurecimento pessoal e valorização profissional, qualificando a formação e alguns se sentem mais preparados e sabem onde buscar a informação se necessário, pois o curso mostrou diferentes possibilidades. Também ressaltam que este permitiu que conhecessem profissionais de Interfaces da Educ., Paranaíba, v.10, n.30, p. 315 - 345, 2019 
outras áreas, bem como suas vivências e obstáculos enfrentados. E que o curso de formação despertou o interesse em adquirir mais conhecimentos e abriu horizontes para trabalhar com o assunto e buscar mais informações sobre o tema. Algo que sempre almejamos quando propussemos o curso é que esse servisse para que os professores em formação inicial e os já graduados pudessem buscar cada vez mais formação nesse sentido e percebessem que eles podem e são capazes de fazer a diferença.

Tardif (2008, p. 287) expõe que “as fontes da formação profissional dos professores não se limitam à formação inicial na universidade; trata-se, no verdadeiro sentido do termo, de uma formação contínua e continuada que abrange toda a carreira docente". Também de acordo com Veiga (2009) e Tardif (2009), a prática e a teoria precisam andar lado a lado na formação de professores, desta maneira

(...) realizada concretamente numa rede de interações com outras pessoas, num contexto onde o elemento humano é determinante e onde estão presentes símbolos, valores, sentimentos, atitudes, que são passíveis de interpretação e decisão que possuem, geralmente, um caráter de urgência. Essas interações são mediadas por diversos canais: discurso, comportamentos, maneira de ser, etc. Elas exigem, portanto dos professores, não um saber sobre um objeto de conhecimento nem um saber sobre a prática e destinado principalmente a objetiva-la, mas a capacidade de se comportarem como sujeitos, como atores e de serem pessoas em interação com pessoas (TARDIF, 2008, p.50).

Como descrito por Uliana (2015) "esse tipo de formação se mostrou um caminho exitoso a ser trilhado tendo em vista formar professores com habilidades e competências para exercer uma prática pedagógica inclusiva", por isso cada vez mais precisamos buscar maneiras de contribuir para formação dos docentes no sentido da inclusão.

\section{Considerações finais}

No presente trabalho foram analisados os questionários inicial e final com o intuito de verificar se as expectativas dos participantes foram Interfaces da Educ., Paranaiba, v.10, n.30, p. 315 - 345, 2019 
alcançadas e quais as contribuições do curso de formação ofertado, bem como, analisar os conhecimentos dos participantes sobre inclusão e tópicos relacionados a esse assunto.

Com a análise dos dados pode-se observar que os professores em formação inicial e continuada das áreas de Biologia, Física, Química e Educação Especial percebem a importância da inclusão de todos tanto no meio social quanto escolar, destacando ainda alguns desses aspectos como vantagens de ter alunos e pessoas incluída nesses meios, consideram também que muitas vezes essa inclusão é excludente, isso por diversos motivos. Ainda nas respostas ao questionário final a grande maioria distiguiu de maneira favorável e pode compreender melhor a integração e inclusão. Quanto as percepções sobre pessoas com deficiência visual pode-se verificar que os participantes já tinham um bom conhecimento sobre o assunto o qual foi ampliado ao longo do curso.

Relacionado as ações para aprimorar a formação de professores frente à inclusão destacadas no início do curso muitas foram relatadas como algo que deve ser ampliado cada fez mais com a oferta de cursos, palestras, disciplinas envolvendo esses tópicos. Algo que consideramos de grande importância, pois percebemos tanto nos destaques das contribuições e pontos positivos o quanto um curso de formação ofertado tanto para professores em formação inicial quanto continuada pode auxiliar na sua formação, bem como muitos salientaram que suas expectativas foram superadas. Referente aos pontos negativos e as expectativas que não foram alcançadas esses servem para que em uma próxima oportunidade, esses possam ser revistos para que possamos melhorar cada vez mais. Portanto, pôde-se ter a certeza de que o aprendizado é contínuo e que os desafios relacionados a inclusão e temas relacionados são muito amplos e precisam ser cada vez mais explorados para que possamos aprimorar a nossa formação, tendendo a uma formação mais humana na perspectiva da educação inclusiva.

Em uma próxima oportunidade serão repensados os tópicos mencionados a serem melhorados, como os questionários, o tempo do curso, 
os assuntos a serem abordados e assim também outros temas relacionados precisam ser cada vez mais explorados para aprimorar os conhecimentos.

\section{Referências}

BASTOS, A. R. B. de; CENCI, A. Desenvolvimento de práticas inclusivas: aportes teórico-práticos para o apoio aos estudantes em estágio de docência. In: MÓL, G. O ensino de Ciências na escola inclusiva. Campos Goytacazes: Brasil Multicultural, 2019, p. 150-168.

BRASIL. Ministério da Educação. Secretaria de Educação Especial (SEESP). Política Nacional de Educação Especial na Perspectiva da Educação Inclusiva. Brasilia: MEC/SEESP, 2008.

Portaria GM/MS n. ${ }^{\circ} 1060$, de 5 de junho de 2002. Política para reabilitação da pessoa portadora de deficiência na sua capacidade funcional e desempenho humano, de modo a contribuir para a sua inclusão plena em todas as esferas da vida social. Brasília: Ministério de Estado da Saúde, 2002.

Ministério da Educação. Proposta de diretrizes para a formação inicial de professores da educação básica em cursos de nivel superior. Brasília: Ministério da Educação, 2000.

CAIMI, F. E.; LUZ, R. N. Inclusão no contexto escolar: estado do conhecimento, práticas e proposições. Revista Educação Especial, Santa Maria, v. 31, n. 62, p. 665-682, jul/set. 2018.

CAMARGO, E. P. de. Saberes docentes para a inclusão do estudante com deficiência visual em aulas de Física. São Paulo: Editora Unesp, 2012.

COSTA, V. B da. A prática social da convivência escolar entre estudantes deficientes visuais e seus docentes: o estreito caminho em direção à inclusão. 2009. 248 p. Dissertação (Mestrado em Ciências Humanas) Universidade Federal de São Carlos, São Carlos, SP, 2009.

Inclusão Escolar do deficiente visual no Ensino Regular. Jundiaí: Paco Editorial, 2012. 188 p.

FIGUEIREDO, R. V. A. A formação de professores para a inclusão dos alunos no espaço pedagógico da diversidade. In: MANTOAN, M. T. E. (Org.). O desafio das diferenças nas escolas. Petrópolis: Vozes, 2008. p. 141-145.

GARCIA, R. M. C. Políticas de inclusão e currículo: transformação ou adaptação da escola? Trajetórias e processos de ensinar e aprender: sujeitos, currículos e culturas. Anais... XIV ENDIPE. 2008. p 582-94.

GARCIA, C.M. Formação de professores para uma mudança educativa. Porto-Portugal: Editora Porto, 1999. 272 p.

MANTOAN, M. T. E. Inclusão, diferença e deficiência: sentidos, deslocamentos, proposições. Revista Inclusão Social, Brasília, v. 10, n. 2, p. 37-46, jan./jun. 2017.

Caminhos pedagógicos da inclusão: contornando e ultrapassando barreiras. 2003a. Disponivel em: Interfaces da Educ., Paranaiba, v.10, n.30, p. 315 - 345, 2019 
http://www.lite.fe.unicamp.br/papet/2003/ep403/caminhos_pedagogicos_d a_inclusao.htm >.Acesso em: 28 ago. 2019.

Inclusão Escolar: O que é? Por quê? Como Fazer?. São Paulo: Moderna, 2003b, 50 p.

MARTINS. L. de A. R.. Reflexões sobre a formação de professores com vistas à educação inclusiva. In: MIRANDA, T. G.; FILHO, T. A. G. O professor e a educação inclusiva: formação, práticas e lugares. Salvador: EDUFBA, 2012. $491 \mathrm{p}$.

MENDES, E. G. A radicalização do debate sobre inclusão escolar no Brasil. Revista Brasileira de Educação, Rio de Janeiro, v. 11, n. 33, p. 387-559, set/dez. 2006.

MITTLER, P. J. Educação inclusiva: contextos sociais. Porto Alegre: Artmed, 2003. 264 p.

MORAES, R; GALIAZZI, M. do C. Análise textual discursiva: processo reconstrutivo de múltiplas faces. Revista Ciência \& Educação, Bauru, v. 12, n. 1, p. 117-128, 2006.

MORAES, R. Uma tempestade de luz: a compreensão possibilitada pela análise textual discursiva. Ciência \& Educação, Bauru, v. 9, n. 2, p. 191$211,2003$.

NETO. A. de O. S. et al. Educação inclusiva: uma escola para todos. Revista Educação Especial, Santa Maria, v. 31, n. 60, p. 81-92, jan/mar. 2018.

ORGANIZAÇÃO DAS NAÇÕES UNIDAS PARA A EDUCAÇÃO, A CIÊNCIA E A CULTURA (ONU). Declaração Salamanca sobre os princípios, política e prática em Educação Especial. Salamanca: UNESCO, 1994.

PACHECO, P. et al. Educação inclusiva: um diálogo com a Educação Básica a partir do Ciclo de Políticas. Revista Educação Especial, Santa Maria, v. 32, p. 1-16, 2019.

SANCHES, I.; TEODORO, A. Da integração à inclusão escolar: cruzando perspectivas e conceitos. Revista Lusófona de Educação, Lisboa, v. 8, n.8, p. 63-83, jul. 2006.

SILVA, W. P. da.; MÓL, G. de S. Dosvox e Jogavox na educação de pessoas com deficiência visual. In: MÓL, G. O ensino de Ciências na escola inclusiva. Campos Goytacazes: Brasil Multicultural, 2019, p. 186-199.

TARDIF, M. Saberes Docente e Formação Profissional. 14 ed. Petrópolis: Vozes, 2012.

O que é saber da experiência no ensino? In: ENS, R. T.; VOSGERAU, D. S. R.; BEHRENS, M. A. (Orgs.). Trabalho do professor e saberes docentes. Curitiba: Champagnat, 2009. p. 25-39.

2008 .

Saberes docentes e formação profissional. 9.ed. Petrópolis: Vozes,

ULIANA, M. R. Formação de professores de Matemática, Física e Química na perspectiva da inclusão de estudantes com deficiência visual: análise de uma intervenção realizada em Rondônia. 2015. $314 \mathrm{f}$. Tese (Doutorado Interfaces da Educ., Paranaíba, v.10, n.30, p. 315 - 345, 2019 
em Educação em Ciências e Matemática) - Universidade Federal de Mato Grosso, Cuiabá, MT, 2015.

VEIGA, I. P. A. A aventura de formar professores. Campinas: Papirus, 2009.

VYGOTSKY, L. S. A defectologia e o estudo do desenvolvimento e da educação da criança anormal. Educação e Pesquisa, São Paulo, v. 37, n. 4, p. 861-870, dez. 2011. 